\title{
FAMÍLIA, ESTADO E PROTEÇÃO SOCIAL: UM ESBOÇO PARA COMPREENSÃO E DEBATE $^{1}$
}

Ana Cláudia Pereira da Paz (UFPI) ${ }^{2}$

Solange Maria Teixeira (UFPI) ${ }^{3}$

RESUMO: O objetivo deste artigo é analisar a relação Família/Estado no sistema de proteção social brasileiro e as mudanças nessa relação, desvendando seus determinantes que estão para além da direção das políticas sociais, uma vez que as mesmas têm relação direta com a concepção de papel do Estado e da sociedade, que se altera em função dos interesses capitalistas e da correlação de forças na luta de classes. Detém-se no exemplo da política de Assistência Social e na centralidade da família nessa política que amplia as responsabilidades das famílias.

Palavras-Chave: Família. Estado. Proteção Social.

\section{INTRODUÇÃO}

A discussão sobre as questões que se estabelecem na relação da família com o bem-estar dos seus membros é ineliminável do processo de compreensão dos sistemas proteção social no Brasil e dos avanços e recuos apresentados pelas políticas sociais. O debate sobre esta relação permite a abertura de reflexões em torno do lugar da família e do cuidado por ela garantido no processo de reprodução social.

Neste debate, considera-se que o modelo de sistema de proteção social e a perspectiva em que a família é tomada dentro desse arranjo formal, apresentam-se como chaves explicativas para estas reflexões. Em vista disso, pode-se apreender elementos para a compreensão do porquê do crescimento da responsabilização da família no tocante a integração social e a complexidade desse processo quando se considera a sua relação com a garantia de direitos.

O objetivo deste artigo é analisar a relação família, Estado e proteção social, o modo como a família é inserida nas políticas sociais contemporâneas, pós-Constituição Federal de 1988, e compreender aspectos determinantes do crescimento das expectativas sociais, em especial das políticas sociais brasileiras, sobre suas funções protetivas que tem gerado ainda mais a

\footnotetext{
${ }^{1}$ Trabalho apresentado no Congresso Brasileiro Ciência e Sociedade (CBCS 2019), promovido pelo Centro Universitário Santo Agostinho, de 03 a 05 de outubro de 2019, em Teresina-PI.

${ }^{2}$ Mestranda do Programa de Pós-Graduação em Políticas Públicas (PPGPP) da Universidade Federal do Piauí (UFPI). Email: anacpaz02@gmail.com.

${ }^{3}$ Pós-Doutora em Serviço Social pela PUC-SP (2009), professora orientadora. Docente do Programa de Pós-Graduação

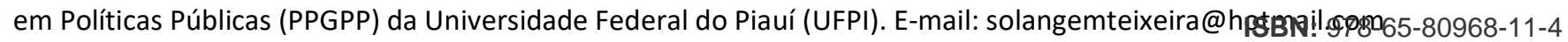




\section{CONQGEESOO CIENCIAESOCIEDADE

responsabilização, sem ou com precários suportes oferecidos. Esses determinantes giram em torno do novo modelo de acumulação capitalista e de regulação estatal, no qual o neoliberalismo é sua expressão político-ideológica e prática, que desde os anos 1990, no Brasil, tem assumido a direção das "reformas" do Estado, que na atualidade são ainda mais regressivas.

\section{METODOLOGIA}

O artigo é resultado de uma pesquisa teórica e utilizou-se da metodologia típica dos estudos bibliográficos - uma revisão de literatura. Por ser qualitativa, estabeleceu critérios de escolha intencional, tais como a seleção de referências que adotam uma discussão crítica sobre a relação família/políticas sociais e que se aproximam com a adotada pelas pesquisadoras, ou seja, que fortaleçam a lógica dos direitos sociais e da família como sujeito de direitos e, portanto, se contrapunham ao familismo típico de nossas políticas. Essa revisão de literatura é parte de um projeto de dissertação de mestrado em desenvolvimento, no Programa de Pós-Graduação em Políticas Públicas da UFPI, que fundamenta esse artigo e fortalece os argumentos que desenvolvemos para firmar nossas hipóteses ou pressupostos de trabalho.

\section{APONTAMENTOS PARA O DEBATE ACERCA DOS RUMOS DA RELAÇÃO FAMÍLIA, ESTADO E PROTEÇÃO SOCIAL}

A relação da família com o bem-estar e o cuidado dos seus membros se dá atravessado por determinações estruturais, políticas, históricas e sociais que condicionam, criam, movimentam e preservam modelos e estratégias de proteção social, dando movimento ao caldo contraditório que se produz na conformação de uma lógica de direito adaptada à dinâmica do capital.

Entendimentos que categorizam as famílias em "capazes" ou "incapazes", "estruturadas" e "desestruturadas", por exemplo, partem de uma concepção que abstrai desse debate os elementos que são externos, mas que exercem influência sobre a família e estão na base da sua compreensão, enquanto importante canal de proteção social. Vincular o debate sobre família e bem-estar ao movimento mais amplo em que este se inscreve traz questões que explicam a persistência das categorizações supracitadas ao mesmo tempo em que as desmistificam.

A dinâmica do processo de construção, estabelecimento e manutenção ou não de um padrão de proteção social é reflexo do desenvolvimento socioeconômico de cada momento 
histórico. Assim, a processualidade de construção, no Brasil, de um modelo de intervenção estatal nas expressões da "questão social" não se dá descolada da conformação dos direitos vinculados ao trabalho assalariado urbano e sua funcionalidade para a reprodução social, sobretudo quando se considera o binômio trabalho-direitos, tão característico da "cidadania regulada" ${ }^{4}$, no Brasil.

Considera-se, nesse contexto, o surgimento do operariado urbano e das lutas trabalhistas, próprias do processo de industrialização, que colocaram na ordem do dia a necessidade do estabelecimento, por parte do Estado, de uma resposta não apenas repressiva, mas também capaz de associar a sua legitimação com o controle da luta de classes.

Ressalta-se que a emergência da burguesia industrial não significou o rompimento com o setor agrário-exportador. Dentro de uma perspectiva de "modernização conservadora" e sob a égide do capitalismo dependente, as respostas aos desdobramentos dessa nova conjuntura caracterizaram-se pela superexploração da classe trabalhadora e pela continuidade da centralização do poder nas classes dominantes locais.

De acordo com a periodização de Draibe (1989), as políticas sociais estabelecidas nos períodos de Introdução e Consolidação de um Sistema de Proteção Social no Brasil voltava-se para indivíduos e segmentos sociais específicos. A cidadania, conforme sustenta Santos (1987), apresenta-se, no pós-30 diretamente associada às ocupações reconhecidas por lei, deixando à margem inúmeros trabalhadores informais e os mais pobres, para os quais se destinava, segundo Sposati (1994 apud YAZBEK, 2012, p.10), um “modelo de regulação pela benemerência".

No tocante a relação com a família, para Teixeira (2013), embora as políticas sociais nesse primeiro momento tenham direcionado suas ações para segmentos específicos, ou mesmo para determinadas categorias profissionais, é possível afirmar que em vários contextos essas ações se dirigiram "à família, uma vez que a unidade familiar favorecia a harmonia social e política e a adaptação do trabalhador ao mundo do trabalho, sendo, portanto, alvo do interesse do Estado e capital" (TEIXEIRA, 2013, p. 80).

Entretanto, não havia uma centralidade na família, ou seja, não se abordava os segmentos no seu contexto familiar e comunitário. Mesmo que as intervenções em "situações-problemas" e em segmentos etários (crianças, adolescentes, idosos) terminassem envolvendo a família, esta era sempre tomada como responsável pelo problema vivenciado, geralmente essa culpabilização

\footnotetext{
4 “a cidadania cujas raízes encontram-se não em um código de valores políticos, mas em um sistema de estratificação

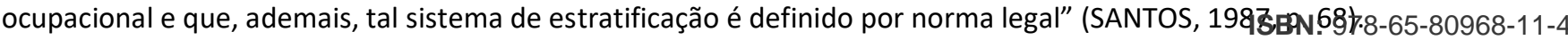




\section{CONGEESSO CIENCIAESOCIEDADE \\ Inovação, Diversidadie e Sustentahilitidade}

recaia sobre as mulheres e seus "arranjos familiares" tidos como desajustados, desestruturados, em crise, incompletos e geradores de patologias.

A família assume centralidade nas políticas sociais no contexto categorizado por Draibe (1989) como de Reestruturação do Sistema de Proteção Social brasileiro, que tem início nos anos de 1980. A partir da Constituição Federal de 1988 assiste-se ao processo regulamentação, via legislações sociais e leis infraconstitucionais, das expectativas historicamente gestadas em torno do núcleo familiar e do seu intercâmbio social. Ressalta-se que esse contexto coincide com amplos movimentos reformistas de políticas públicas que lutavam pelo direito ao convívio familiar e comunitário, em oposição ao modelo institucionalizante, segregacionista, repressor, enclausurador.

Todavia, já nas décadas seguintes há a adesão do governo brasileiro ao modelo neoliberal, em ampla expansão mundial, colocado com a única maneira de superar as crises e retomar o crescimento. Com uma política econômica de restrição de gastos públicos, em especial os sociais, esse modelo vem gerando empecilhos reais a efetivação dos princípios constitucionais na medida em que ataca diretamente as políticas sociais universalizantes, acusadas de gerar déficits fiscais, não reconhecer o mérito, gerar ócio, preguiça, não amor ao trabalho e desresponsabilização individual e famíliar.

Em contrapartida, o modelo neoliberal, fortalece e incentiva o pluralismo de bem-estar social, na lógica liberal de que a proteção social deve ser responsabilidade de todos, família, mercado, sociedade civil, e o Estado aos estritamente pobres, de maneira subsidiaria. Assim, difunde-se o princípio de que essas instituições devem assumir parte da responsabilidade com a proteção social, em parceria ou não, com o Estado.

No contexto de avanços constitucionais e de movimentos reformistas das políticas sociais de um lado, e de "contrarreformas" neoliberais e de de apelo para a família assumir responsabilidades, de outro, é que as legislações brasileiras vão incluir a família na proteção social. Essa inclusão se dá sob influência de discursos internacionais e nacionais de que em períodos de crises e incapacidades do Estado, as parcerias são as únicas chances de manter ativo e presente um sistema de proteção social, reestruturado e em novos moldes. Portanto, as políticas sociais que assumem centralidade na família traduzem, em seu desenho e operacionalização, essas contradições. Dentre essas políticas, destacamos a de assistência social, por ser objeto da pesquisa em andamento. 
O desenho e operacionalização da política de Assistência Social, por exemplo, prevê ampla participação da família na promoção do bem-estar dos seus membros, ao mesmo tempo, em que a toma como central para pensar os serviços socioassistenciais, facilitando seu acesso a rede de serviços referenciado no trabalho social com famílias, na proteção social básica e especial.

Notadamente, os instrumentos formais da política de Assistência Social ${ }^{5}$ materializam elementos de natureza progressista, na medida em que compreendem a família como objeto de proteção social, mas também traduzem, ora no desenho, ora na operacionalização, o caráter contraditório que marcam os modelos de política social engendrados sob mediações "contrarreformistas", de redução do campo de intervenção da política, minimizada pelos congelamentos e cortes orçamentários, e a expectativa que a família cuide, assista, eduque e mantenha a sobrevivência do seu grupo.

O reconhecimento do hibridismo, das contradições e do caráter familista ${ }^{6}$ assente na política social brasileira, decorre da tentativa de superação de interpretações simplistas acerca das expressões do sistema de proteção social estabelecidas nos marcos da sociedade do capital. A Política de Assistência Social, enquanto política social é, portanto, eivada pela contrariedade que encerra o campo de disputas próprio do sistema capitalista e, mais especificamente, pelas características históricas das intervenções do Estado nas refrações da "questão social" no Brasil.

Importa destacar que a família sempre esteve ao lado do Estado na conformação do bemestar, até mesmo durante o período anterior ao estabelecimento de um sistema de proteção social. De acordo com Teixeira (2012), a mudança está no simples fato de que antes a atuação da família ocorria apenas na esfera informal, pautadas por laços de afinidade, parentesco e solidariedade e na atualidade essas funções familiares ganham contornos mais expressivos e regulamentações formais.

Desta feita, na compreensão da inter-relação entre família, Estado e proteção social, suas principais características, posições, persistências e (re)atualizações - transvestidas de outras

\footnotetext{
5 Política Nacional de Assistência Social - PNAS, em 2004, Norma Operacional Básica do Sistema Único de Assistência Social-NOB/SUAS, em 2005 - atualizada em 2012 - atualização da Lei Orgânica de Assistência Social - LOAS, pela lei № 12.436 , de 2011

${ }^{6}$ Tendência que aposta na capacidade natural da família para o cuidado e proteção dos seus membros, correspondendo a uma menor provisão por parte do Estado. Baseia-se no princípio de subsidiariedade do Estado, de modo que o Estado atua somente quando os canais tidos como naturais (família e mercado) falham. Nesse sentido, a família deve buscar por conta própria, através das redes de apoio informais ou mesmo via mercado, garantir o bemestar dos seus membros (MIOTO, 2010).
} 
nomenclaturas e roupagens - são mantidas e renovadas. Para compreendê-las é preciso refletir sobre os aspectos ligados ao movimento do capital e ao contexto de correlação de forças sociais estabelecido em cada momento histórico. No caso especifico dos países de capitalismo dependente importa considerar ainda, para fins de compreensão, que "a forma dependente de Estado possui características presentes nos Estados capitalistas somadas a elementos particulares de formação dependente" (MAURIEL, 2018 p.251).

Nesse sentido, em que pese os avanços trazidos no contexto progressista, marcado pela legitimação de direitos sociais e pelo reconhecimento da família objeto de proteção social, as tensões presentes no processo de redefinição do papel do Estado, em tempos de neoliberalismo e hegemonia do capital financeiro, operaram um processo de remodelamento no campo das políticas sociais. Consequentemente, a relação da família com a proteção social assume "novas" nuances e a forma como a unidade familiar é tomada dentro dessa dinâmica tende a assumir contornos favoráveis ao capital, que tendem a sobrecarregá-la.

O estabelecimento do Neoliberalismo como uma das estratégias de enfrentamento da crise do capital nos anos de 1970 provocou, nos países de capitalismo avançado, o questionamento da legitimidade dos modelos de welfare state e a progressiva redefinição do papel do Estado no campo das garantias sociais. Essa processualidade legitimou o processo de reestruturação produtiva e reativou questões ligadas ao enfrentamento das expressões da questão social e acesso de bem-estar.

Essa tendência chega ao Brasil sobretudo a partir de 1990 sob a mesma inflexão. Capitaneada pelo discurso de austeridade na política econômica, a necessidade de se limitar o sistema público de proteção social é colocada na ordem do dia. Ainda em processo de consolidação, tendo em vista o processo recente de redemocratização, o sistema de proteção social brasileiro é posto na mira das mudanças com vistas ao atendimento dos ditames do capital, com isso

Os direitos sociais perdem identidade e a concepção de cidadania se restringe; aprofundase a separação público-privado e a reprodução é inteiramente devolvida para este último âmbito; a legislação trabalhista evolui para uma maior mercantilização (e, portanto, desproteção) da força de trabalho; a legitimação (do Estado) se reduz à ampliação do assistencialismo (SOARES, 2002, p, 13)

Para a política social, a grande orientação é a focalização das ações, com estímulos aos fundos sociais de emergência, e a mobilização da 'solidariedade' individual e voluntária, bem como das organizações não-governamentais prestadoras de serviços de atendimento, no âmbito da sociedade civil (BEHRING, 2008, 2008, p. 65) 
A desestruturação Estatal e a perda de direitos ampara a afirmação dos canais naturais de proteção, a partir da revalorização das redes de solidariedade. O Estado passa a atuar apenas quando a família exaure a sua capacidade de suprir suas necessidades, seja através das redes de apoio - vizinhança, amigos, família extensa - seja via mercado.

Ademais, numa sociedade em que o padrão de acesso a garantias formais de proteção social se assenta no trabalho assalariado, os desdobramentos nefastos da "ofensiva contra o trabalho", como o desemprego, a desproteção, precarização do trabalho, trazem efeitos perversos para o acesso a garantias socais públicas. O "ressurgimento" das velhas estratégias de enfrentamento das situações de vulnerabilidade social ganha ressonância, na medida em que o caráter fragmentado, focalizado e residual das ações sociais públicas não dão conta dos custos sociais dessa dinâmica.

A perspectiva de resolução das carências e necessidades na esfera particular, de forma privada, legitima o discurso da família como o espaço natural de bem-estar, apoio e ajuda, apreensão que tende a universalizar de forma a-histórica um padrão de respostas esperadas pela família ao mesmo tempo em que abstrai a complexidade das relações que a envolvem.

Nesse sentido, é preciso recordar que as famílias existentes não são homogêneas e imutáveis. A fragmentação e a heterogeneidade são características presentes nas diferentes fases do ciclo de vida, nas formas proteção e cuidado, na maneira que os vínculos se estabelecem na integração social e no modo de educar e socializar que as famílias estabelecem no seu interior (SARACENO, 1992). Além disso, o cenário político e econômico interfere cotidianamente na vida das famílias, no acesso a bens e serviços e na sua capacidade de garantir cuidado. As famílias estão menores, com trabalhos precários, dificuldades de educar e socializar seus membros em contexto de ampliação da violência, do crime organizado, das milícias, do tráfico de drogas e de menos Estado para atender suas demandas, especialmente as mais vulneráveis.

Descolar para o campo individual e da família a responsabilidade por questões cujas raízes estão assentadas numa ordem social excludente e desigual sobrecarrega a unidade familiar e agrava o contexto de vulnerabilidade. A existência de situações comuns a muitas famílias ligadas à violência, ao abandono, a inseguranças e à "incapacidade" em garantir, de forma efetiva, a socialização primária dos seus, são postas, dentro dessa lógica, como questões de ordem singular não como desdobramentos da base fundante do sistema capitalista. 


\section{CONGEESSO CIENCIAESOCIEDADE Inovação, Diversidadie e Sustentahilitidade}

A individualização dos riscos, a sobrevalorização da solidariedade, a privatização do trato das expressões da "questão social", segundo Haroldo Abreu (2008), dissocializa e despolitiza a cidadania. Nessa "cidadania desfigurada", "a miséria [...], a violência [...], passa a ser enfrentada pelos 'homens de bem', pela responsabilidade individual e pelas disponibilidades privadas de cada um [...] isentando as condições de existência da ordem social e política" (ABREU, 2008, p. 325).

Todavia, essas estratégias privadas, familiares e comunitárias são limitadas, estão exauridas e são incapazes de romper ciclos de pobreza, de violações e garantir cidadania e efetivação de direitos sociais.

\section{CONSIDERAÇÕES FINAIS}

A relação família/políticas públicas se alteram em diferentes conjunturas. Na formação dos sistemas de proteção social públicos, nos países capitalistas ocidentais, a família nunca deixou de exercer funções protetivas, fundamentais ao capitalismo, pois especialmente as mulheres dedicavam-se as atividades domésticas e de cuidados dos seus maridos, filhos e pais, cuidando da reprodução atual e futura da força de trabalho. Porém, o Estado assumia as responsabilidades de gestor e ofertante dessa proteção social, mantida pelo fundo público, no qual todos os contribuintes custeiam. Uma forma de socializar os custos da reprodução social com a sociedade.

Como as reformas neoliberais, da nova etapa do modelo de acumulação capitalista financeirizado, reestruturado e neoliberal - o capital se recusar a partilhar essa responsabilidade de financiar a proteção social e encontra nas políticas sociais espaço para sua reprodução ampliada, pressionando para as privatizações, refilantropização, ou seja, a redução da proteção social pública, deixando margem para o Estado oferecer essa proteção como mercadoria a ser comprada e aos pobres, um Estado mínimo compartilhado com as ONGs, família e comunidade.

A centralidade da família nas políticas sociais não fugirá dessa influência de oferecer um mínimo de assistência e impulsionar e de fortalecer e potencializar as funções protetivas da família, sua intervenção e responsabilização pela proteção dos seus membros, independentemente das condições de vulnerabilidade que enfrentam.

Conclui-se, portanto, que essa tendência e orientação da política não podem ser compreendidas fora do contexto de avanço do capitalismo, na atual fase de desenvolvimento. 


\section{CONGRESSO BRASILERO

\section{REFERÊNCIAS}

ABREU, A. Para além dos Direitos. Cidadania e hegemonia no mundo moderno. Rio de Janeiro: Editora UFRJ, 2008.

BERING, E.R. Brasil em contra-reforma- Desestruturação do Estado e perda de direitos. 2 ed. São Paulo: Cortez, 2008)

DRAIBE, S. O Welfare State no Brasil: características e perspectivas. Ciências Sociais Hoje. Ed. Revistas dos Tribunais, ANPOCS, São Paulo, Vértice, p 13-60, 1989.

MIOTO, R. C. T. A família como referência nas políticas públicas: dilemas e tendências. In: MOURA, M. M. D. Família contemporânea e saúde: significados, práticas e políticas públicas. Rio de Janeiro: Fiocruz, p. 51-60, 2010.

MAURIEL. A. P. Estado e expropriações no capitalismo dependente. In: BOSCHETTI, I. (Org). Expropriações e direitos no capitalismo. São Paulo: Cortez, 2018. P. 233-264.

SANTOS, W. G. dos. Cidadania e Justiça: a política social na ordem brasileira. Rio de Janeiro, Campos, 1987.

SARACENO, C. Sociologia da família. Lisboa: Editorial Estampa, 1992

SOARES, L.T. Os custos sociais do ajuste neoliberal na América Latina. 2 ed. São Paulo, Cortez, 2002)

TEIXEIRA, S. M. A centralidade da família nas políticas sociais e o trabalho social com famílias. In: LIMA, A. J; FERREIRA, M. D. M.; VIANA, M. R. Políticas Públicas e Cidadania: temas em debate. Teresina. EDUFPI, p. 101-118, 2012.

TEIXEIRA, S. M. A família na política de assistência social: concepções e as tendências do trabalho social com famílias nos CRAS de Teresina-PI. Teresina: EDUFPI, 2013.

YASBEK, M. C. Pobreza no Brasil contemporâneo e formas de seu enfrentamento. Serviço Social e Sociedade. São Paulo. N 11, p. 228-322, abril/jun. 2012. 